\title{
Numerical Simulation of Multistep Warm Extrusion Forming for the Outer Race of Universal Joint
}

\author{
Liqin Shen ${ }^{1, *}$ and Michele Bellus ${ }^{2}$ \\ ${ }^{1}$ School of Rail Transportation, Nanjing Vocational Institute of Transport Technology, Nanjing 211188, China \\ ${ }^{2}$ Salvagnini Italia S.p.A, Road Guido Salvagnini 51, Sarego (VI) 36040, Italy \\ Received 10 October 2018; Accepted 10 December 2018
}

\begin{abstract}
Hot forging and machining by forging press is the traditional processing method of automotive universal joint outer race. The method has several disadvantages, such as high energy consumption, over-burning and oxidation tendency of the workpiece, large machining allowance, low surface quality, and poor mechanical properties. To solve the problem of low forming quality caused by the traditional processing method of outer race, a multistep warm extrusion forming process was proposed. The optimization of forming process parameters and the quality of this method was discussed in this study. The warm extrusion process was selected through process comparison and analysis. The initial billet size model was designed by applying the principle of constant volume, and four types of solutions were designed with the multistep combination of forward extrusion, upsetting, and backward extrusion. On the basis of finite element analysis method and metal forming flow theory, the numerical simulation was conducted by using the computer aided engineering (CAE) software Deform. The influence of billet diameter, initial extrusion temperature, number of working procedures, and die structure on the material flow, damage, temperature, and stress state in the forming process of outer race was analyzed. The optimal forming solution was obtained after optimization. Results demonstrate that the diameter of the outer race billet with this size is too small and tends to cause folding defects. The optimized billet is $960 \mathrm{~mm} \times 100 \mathrm{~mm}$. When the initial extrusion temperature is high, the forming load is small and the forming quality is poor. Under the premise that the forming quality is guaranteed, the temperature is reduced as much as possible, and the optimized initial extrusion temperature is $800{ }^{\circ} \mathrm{C}$. The increase in working procedure can reduce the maximum forming force, yet with slight effect. High quality can be obtained by the technology of first forward extrusion to the rod and then backward extrusion to the head. This study provides reference values for the warm extrusion forming of cup/rod-shaped parts.
\end{abstract}

Keywords: Outer race, Warm extrusion, Numerical simulation, Deform

\section{Introduction}

The outer race is a key part of a car's constant velocity universal joint with complex shape and belongs to the typical cup and rod part. The outer race bears a strong rotating torque and the axial tension caused by the sliding of the inner ball cage while in rotation when the car is moving. Moreover, the bending torque on the rod is generated by vehicle steering. Therefore, the outer race has high requirements for compressive, shear, and tensile strength. This type of axial product bearing an alternating load is required such that the metal fiber streamline of its forgings is axially distributed in accordance with the shape to increase the strength and fatigue life.

The traditional machining method of the outer race is hot forging by forging press, and then the required dimensional precision can be achieved by machining. The traditional processing method has relatively simple principles and a clear process, and such production technology has developed maturely. However, the traditional hot forging deformation has numerous disadvantages, such as high energy consumption; overheating, over-burning, oxidation, and decarbonization tendencies of the workpiece;

*E-mail address: kfxdmslq@163.com ISSN: $1791-2377$ @ 2018 Eastern Macedonia and Thrace Institute of Technology. All rights reserved. doi:10.25103/jestr.116.20 large machining allowance; low surface quality and comprehensive mechanical properties of forgings; and poor labor conditions. In particular, considerable machining after forging causes the metal flow line to be cut off, reducing the mechanical properties of the product. Therefore, the outer race which be produced by the traditional production process have several defects, such as unstable quality and poor performance.

The technological process cannot meet today's needs due to the shortcomings of traditional processing methods. Warm forming process is an effective method for solving the abovementioned problems and has been applied in the production of numerous mechanical and automotive products in recent years. High precision requirements and large differences in cup and rod size are required due to the complex shape of the outer race. However, the design and optimization of the warm extrusion forming process restrict the popularization of the technology.

Warm extrusion is a process in which the billet is formed above the room temperature and below the recrystallization temperature. This forming process is between hot and cold extrusions. Warm extrusion forming has lower temperature and better working conditions than hot extrusion; it reduces flow and energy loss, minimizes the possibility of oxidative burning loss, and can help produce forge pieces with improved size precision and surface roughness and fine 
structure [1]. Warm extrusion forming involves a higher forming temperature than cold extrusion, which increases plasticity and greatly decreases deformation resistance; this process reduces production cost and increases production efficiency because it does not need annealing and phosphorous saponification processes before forming [2]. Warm extrusion technology has the advantages of cold and hot extrusion and avoids the disadvantages of both. Therefore, the technology has been frequently studied and applied worldwide in recent years.

The warm extrusion forming method of outer race was proposed in this study through the comparative analysis of processes. On the basis of finite element analysis (FEA) method, numerical simulation was conducted by using the computer aided engineering (CAE) software Deform. Moreover, the influences of billet diameter, initial extrusion temperature, number of working procedures, and die structure on the material flows, damage, temperature, and stress state in the forming process of outer race were analyzed. This study aims to obtain an optimal warm extrusion forming process of outer race and provide a reference for the study on the warm extrusion forming and die structure design of cup/rod-shaped parts.

\section{State of the art}

FEA is a method for evaluating a static or dynamic physical object or system through finite element. An object or system is decomposed into a geometric model of several interconnected, simple, and independent points in this method. The number of independent points is finite, which is the reason the method is called finite element. The equilibrium equations are derived from the actual physical model and then solved. FEA replaces complex problems with simple ones and then solves them. As the actual problem is replaced by a simple one, the solution is an approximate one. In fact, obtaining accurate solutions for most practical problems is difficult. Finite element is highly accurate and can adapt to various complex shapes; thus, it has become an effective means of engineering analysis.

$\mathrm{Li}$ [3] simulated the radial warm extrusion process of tie rod in three stages through one finite element simulation software and obtained the billet temperature change curve and flow situation of the radial extruded metal after analyzing the simulation results. The feasibility of the new process was verified by the process test on the press, but the damage of the die was not analyzed. Wang [4] conducted an in-depth theoretical analysis on the warm extrusion forming process of cup-shaped parts and initially proposed the compound forming process scheme of warm forming and then cold forming. However, the study failed to compare the multiple possibilities of the combined warm and cold forming processes. On the basis of the structure characteristics and material properties of car cross shaft parts, Shi [5] designed a set of closed forging warm extrusion forming processes, simulated the warm extrusion forming process of the cross shaft under $780{ }^{\circ} \mathrm{C}$ of processing environment through Deform software, verified the feasibility of the process scheme by analyzing the simulation results, and optimized the design of the closed forging die of cross shaft. Su [6] investigated the influence of the technological parameters of warm extrusion forming on the extrusion process and die wear. He obtained the optimum technological parameter combination of warm extrusion forming through an orthogonal experiment with the forming load as the evaluation index. He simulated and compared die wear with the actual situation and proposed a method for reducing die wear. The present study selected the forming load as the main evaluation index and the only parameter that affected the actual forming quality index.

Sheljaskow et al. discussed friction and lubrication problems during warm forging of steel and developed the optimal friction and lubrication scheme. They considered the friction but not some factors, such as temperature and load [7]. Eghbali B [8] observed the equal diameter angle extrusion process of low carbon steel and obtained the influence of process parameters on the microstructure of extruded parts. Yoon [9] investigated the warm forming process of $\mathrm{Al}-\mathrm{Mg}-\mathrm{Si}-\mathrm{Cu}$ alloy and proposed a reasonable process path. Yoon [10] explored the warm forging of AZ80 alloy for automobile and derived the corresponding process path. Yoon [9] and Yoon [10] analyzed the warm forging process of the alloy, but the combined process was not considered to be a parameter. Through a study of the softening, wear, and life of molds during warm forming, Choi [11] forwarded a method to predict the plastic deformation and wear of molds. Martinkovic [12] conducted a computer numerical analysis of closed die forging and obtained the influence law of temperature on deformation. Liu [13] described the salt fog corrosion law of the sprocket of $40 \mathrm{Cr}$ steel under extrusion forming temperatures of 550 , 650 , and 750 . Yang [14] evaluated the structural strength and service life of hot extrusion die through a numerical simulation of mold wear in each working cycle. Torkian [15] showed the effect of multi- and sub-channel angular temperature extrusion on the mechanical properties of WE43 magnesium alloy and found that the hardness increases with the channel number. Liu [13], Yang [14], and Torkian [15] analyzed the corrosion, strength life, and hardness of the warm extrusion forming method only from a single examination target, respectively.

All of the abovementioned analyses proposed that warm extrusion is an effective method for solving complex cup and shaft parts and invetigated the process parameters and forming quality. Other studies have considered the perspective of process parameters, such as temperature, load, and friction. Furthermore, other researchers have analyzed the aspects of forming quality, such as wear, strength, life, hardness, and other influencing factors, whereas others investigated forming from the perspective of die structure. Scholars all over the world have researched on process parameters and forming quality, but the technology is not fully mature; thus, several problems must be solved. In addition, these scholars have conducted studies from one of two basic factors or parameters, thereby failing to achieve a comprehensive research. Few scholars have thoroughly solved the forming process and quality problems of outer race parts, such as temperature deformation, deformation degree, mold selection, and product precision during extrusion. The rationality of the warm extrusion forming process is the most important factor that affects the quality of products and the service life of molds for outer race parts with complex shapes, large difference in cup and rod sizes, and high precision requirements. The key points of process design are how to arrange the sequence and deformation degree of each process and the cohesion and cooperation between processes reasonably and how to control the material flow, damage, temperature, stress, and strain in the forming process.

To solve the abovementioned technical problems, this study forwarded a type of the warm extrusion forming 
process for automobile universal joint outer race, designed and compared four types of forming process, conducted numerical simulation analysis on the multistep forming process using the advanced FEA software Deform, evaluated the effect factors of the forming quality, and improved the forming process.

The remainder of this study is organized as follows. Section 3 describes the forming requirements of outer race, constructs the billet model, and designs the initial constraint of the FEA of the warm extrusion of outer race. Section 4 optimizes the billet diameter of the warm extrusion on the model through numerical simulation analysis, investigates the initial extrusion temperature and the extrusion process, optimizes the mold structure, and obtains the optimization solution. The last section summarizes the study and provides relevant conclusions.

\section{Methodology}

The outer race parts are composed of steel C45E4, which is a type of carbon structural steel with a relatively high strength. the plastic deformation of outer race should have sufficient plasticity and low deformation resistance. Fig. 1 exhibits that the overall shape of the outer race is relatively complex and the size is relatively large. If forging is performed with multiple extrusion processes, then the tonnage requirement of the hydraulic press is relatively small. Steel C45E4 of outer race materials has good forging performance and very good material liquidity when heated to $800{ }^{\circ} \mathrm{C}-1000{ }^{\circ} \mathrm{C}$, which provides possibility for the longdistance flow of extrusion die forging inner cavity. Multistep Warm Extrusion Forming is conducive for retaining the material structure, thereby ensuring the mechanical properties of the material and improving the service life of the parts.

The initial billet was designed on the basis of the principle of volume invariance, and the subsequent multistation forming solutions were formulated in accordance with the diameter of the initial billet. The four solutions are as follows.

Solution 1: $\varphi 40 \mathrm{~mm} \times 220 \mathrm{~mm}$ of billet was used, and the forging temperature was $800{ }^{\circ} \mathrm{C}$. First, forward extrusion was applied to the rod. Second, the header was upset. Finally, forward extrusion was applied to the head.

Solution 2: $\varphi 60 \mathrm{~mm} \times 100 \mathrm{~mm}$ of billet was used, and the forging temperature was $800{ }^{\circ} \mathrm{C}$. Forward extrusion was initially applied to the rod and then to the head, as shown in Fig. 2.

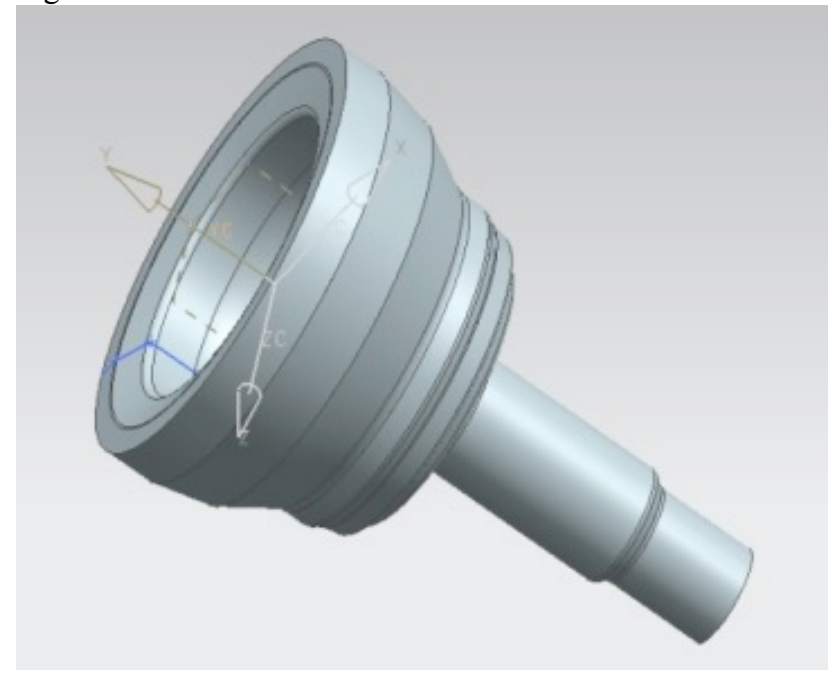

Fig. 1. Extrusion workpiece of the outer race

Solution 3: $\varphi 60 \mathrm{~mm} \times 100 \mathrm{~mm}$ of billet was used, and the forging temperature was $900{ }^{\circ} \mathrm{C}$. Forward extrusion was initially applied to the rod and then to the head.

Solution 4: $\varphi 60 \mathrm{~mm} \times 100 \mathrm{~mm}$ of billet was used, and the forging temperature was $800{ }^{\circ} \mathrm{C}$. Forward extrusion was applied to $\varphi 23 \mathrm{~mm}$ of the rod for the first time and to $\varphi 28 \mathrm{~mm}$ of the rod for the second time. Then, upsetting was conducted. Finally, backward extrusion was applied, as shown in Fig. 3.

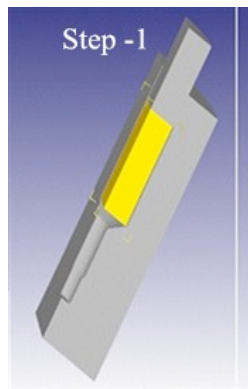

(a)

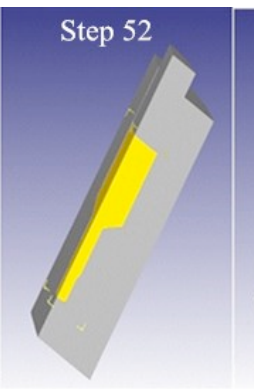

(b)

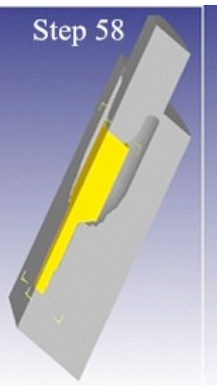

(c)

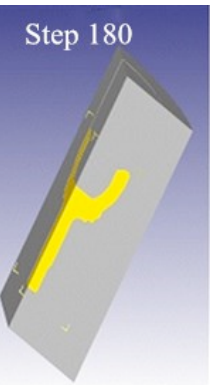

(d)

Fig. 2. Extrusion stage of Solution 2. (a) Billet. (b) Forward extrusion. (c) Backward extrusion. (d) Finished

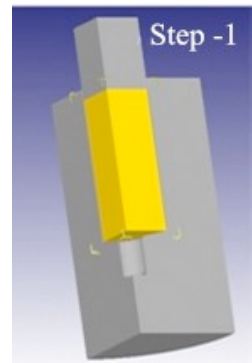

(a)

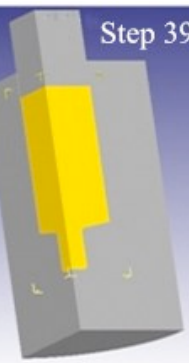

(b)

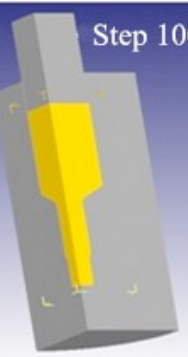

(c)

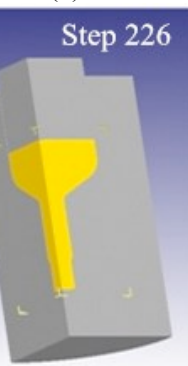

(d)

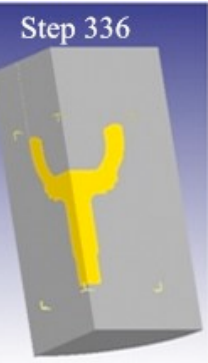

(e)

Fig. 3. Extrusion stage of Solution 4. (a) Billet. (b) Forward extrusion to rod for the first time. (c) Forward extrusion to rod for the second time. (d) Upsetting. (e) Backward extrusion 
The four types of warm forming process were analyzed using Deform tools. On the basis of the product symmetry, a quarter of the real billet was selected, and the grid number was set to 50000. Moreover, on the basis of the actual production, the movement rate of the punch was set to $50 \mathrm{~mm} / \mathrm{SEC}, \mathrm{DIN}-45 \mathrm{C}$ in the software database was selected as the material, and the coefficient of friction between the die and billet was set to 0.25 . The metal flow, stress field, strain field, temperature field, damage field, and load changes of each forming process were obtained.

\section{Result Analysis and Discussion}

\subsection{Optimization of warm forming billet diameter}

For the determination of billet size, Solution 1 is a slender $\operatorname{rod}$ of $\varphi 40 \mathrm{~mm} \times 220 \mathrm{~mm}$, and Solution 2 is a short thick rod of $\varphi 60 \mathrm{~mm} \times 100 \mathrm{~mm}$.

For the extrusion to rod with a slender rod $(\varphi 23$ and $\varphi 28 \mathrm{~mm}$ ), an appropriate extrusion deformation degree is noted due to the small diameter difference between the billet and the extrusion part rod. The defects are not easy to see, which is conducive to the first step of slender rod extrusion forming, as shown in Fig. 4. However, the billet produces a double-drum shape and is folded in the second step of head upsetting due to the small diameter, large height, and large upsetting ratio of the billet, which seriously affect the product quality and performance.

Solution 2 uses the thick short rod billet to perform extrusion forming. For rod part extrusion, a large deformation degree is observed when the $\varphi 60 \mathrm{~mm}$ billet is extruded to a $\varphi 23 \mathrm{~mm}$ billet because the $\varphi 23$ and $\varphi 28 \mathrm{~mm}$ rod is formed through one extrusion. Hence, the metal flow is difficult, and the defaults tend to appear in the rod part. To decrease the difficulty of metal flow, the author adjusts the original $180^{\circ}$ extrusion angle at the junction of $\varphi 28$ and $\varphi 23 \mathrm{~mm}$ rod part, adds the transition section, and reduces the extrusion angle to $60^{\circ}$. The added metal can be removed in subsequent machining and its strength is slightly reduced. However, this position has minimal influence on the overall performance of the product due to the low bearing requirement. The minimal difference in diameter, drum shape, and other conditions do not appear in the subsequent backward extrusion, as shown in Fig. 5.

A comparison shows that Solution 2 has fewer forming steps than Solution 1, has no defects in the extrusion process, and fully meets the design requirements. Therefore, the rod billet with the size of $60 \mathrm{~mm} \times 100 \mathrm{~mm}$ is preferred.

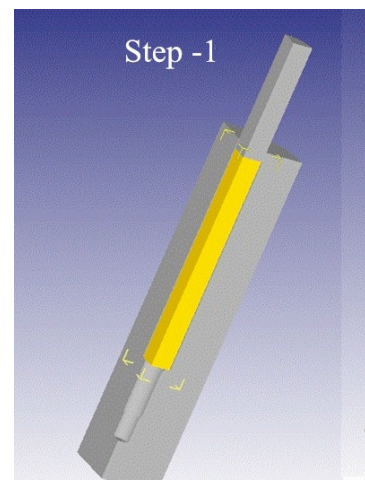

(a)

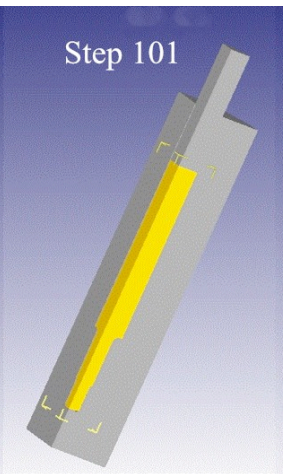

(b)

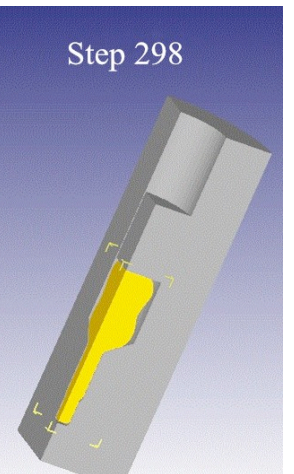

(c)

Fig. 4. Extrusion rod part of Solution 1.(a) Billet. (b) Extrusion to rod part. (c) Head upsetting

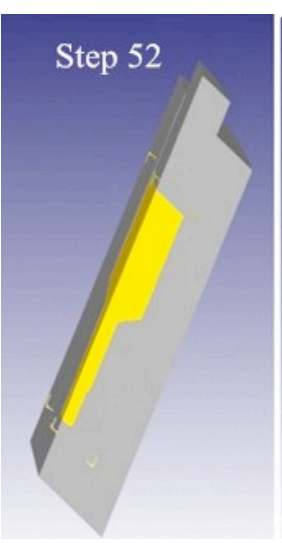

(a)

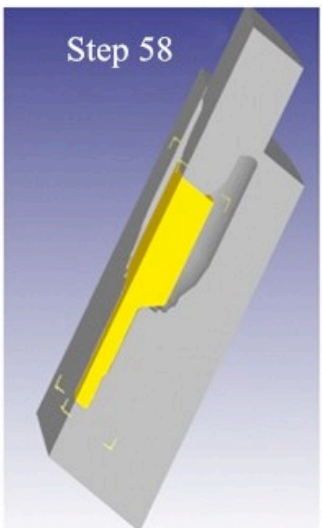

(b)

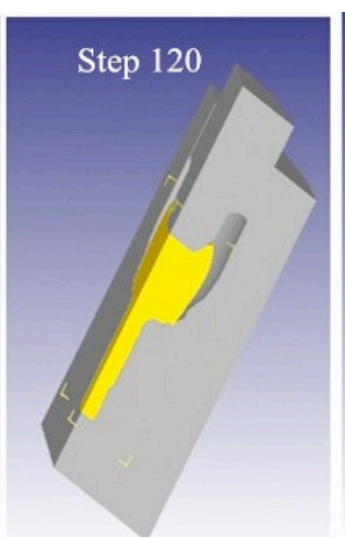

(c)

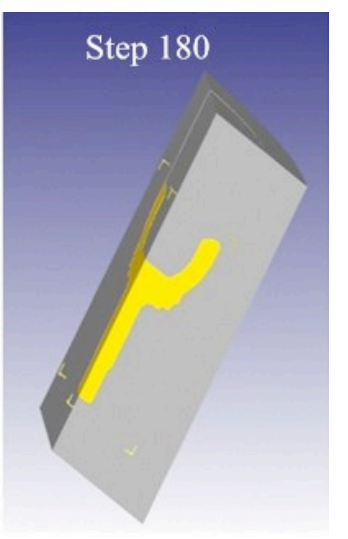

(d)

Fig. 5. Deformation process of Solution 2. (a) Rod part extrusion. (b) Head backward extrusion starts. (c) Head backward extrusion is being conducted. (d) Head backward extrusion ends

\subsection{The initial extrusion temperature of warm forming}

The initial temperature of extrusion billet has a great influence on die temperature and metal deformation resistance. Therefore, two initial extrusion temperatures of warm forming (namely, $800{ }^{\circ} \mathrm{C}$ in Solution 2 and $900{ }^{\circ} \mathrm{C}$ in Solution 3) were proposed in the study. The forming processes of the two types of solutions were analyzed, and their damage, load, and metal flow condition were obtained.
Deform provides a unique damage analysis. This analysis can show the distribution of damage value in the deformation area of the workpiece and assess the dangerous area. The damage value analysis can predict the fracture of the material in tensile state. The larger the damage value, the greater the risk of fracture. The damage value is obtained through a comprehensive calculation of the equivalent strain and stress distribution. Therefore, the area with high damage 
value distribution corresponds to the area with high strain and stress value distribution and is the dangerous area of plastic deformation.
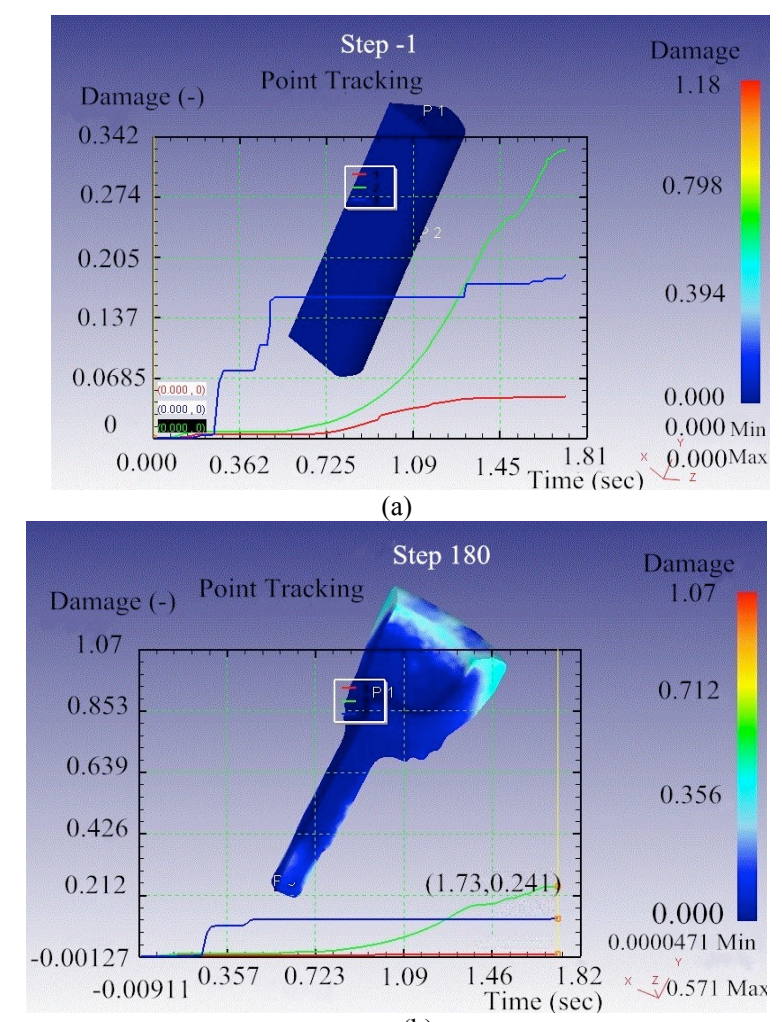

(b)

Fig. 6. Damage value distribution of Solutions 2 and 3. (a) Damage value change curve of the sampling points and Solution 3. (b) Damage value change curve of Solution 2

P1 was obtained from the upper end face of the billet, P2 was acquired from the middle outer surface, and P3 was procured from the lower end face. The three points were selected as samples for collection. Figure 6 shows the curves of damage values corresponding to the three points of the two solutions. Fig. 6 presents that the maximum damage value of Solution 2 is 0.241 of the middle outer surface and the maximum damage value of Solution 3 appears on the middle outer surface, being 0.326 . The other two points are smaller than the point at the middle surface. $\mathrm{P} 2$ at the middle and outer surfaces has a maximum damage value, indicating that the metal is prone to fracture due to large deformation. Such result is consistent with the deformation trend of this part under extrusion swelling at the end of the back extrusion head. The comparison result shows that the damage value of Solution 2 is less than that of Solution 3. Therefore, from the perspective of damage alone, Solution 2 is superior to Solution 3.

The size of the forming load determines the energy consumption and the die stress of the required equipment. Fig. 7 illustrates the punch load curves of Solutions 2 and 3.

As shown in Fig. 7, the maximum carrying capacity $\mathrm{F}$ is $1390 \mathrm{KN}$ in the movement direction of the punch in Solution 2. As $1 / 4$ billet is used for Deform analysis, its actual load is four times of $\mathrm{F}$, that is, $5560 \mathrm{KN}$. Moreover, the maximum carrying capacity of the punch in Solution 3 is $960 \mathrm{KN}$ and its real load is $3840 \mathrm{KN}$. It shows that, the higher the initial extrusion temperature is, the smaller the load is. The reason is that the higher the metal temperature, the lower the deformation resistance of the metal, the easier the recovery and recrystallization, and the easier the deformation after the machining hardening effect is offset. Therefore, from the perspective of reducing die force and equipment tonnage, a high initial extrusion temperature should be adopted. In other words, Solution 3 is preferred.

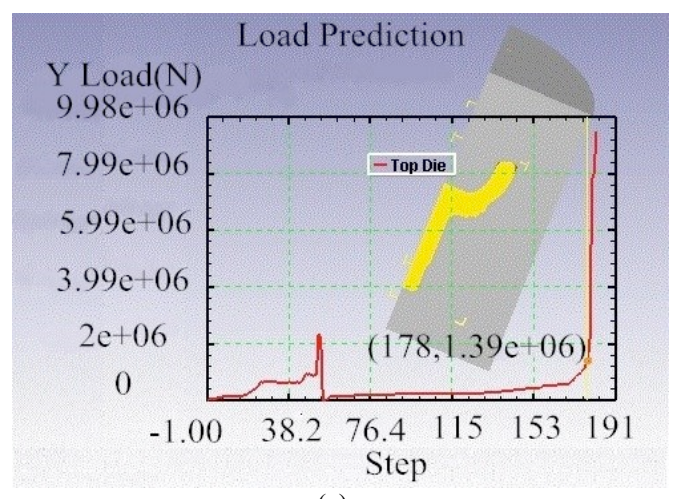

(a)

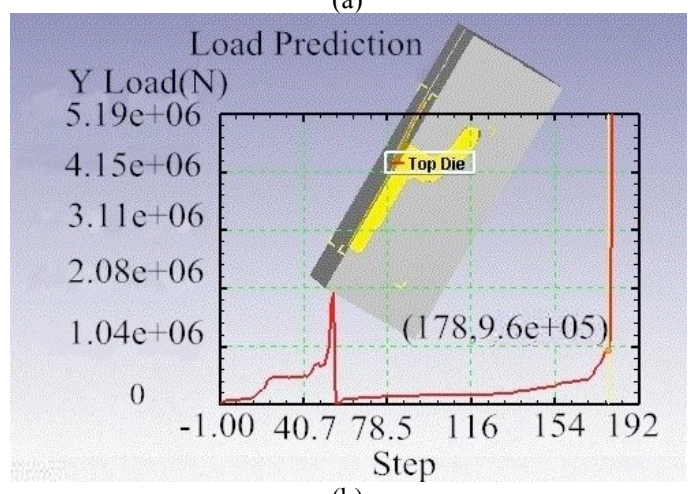

(b)

Fig. 7. Punch load stroke curves of Solutions 2 and 3. (a) Punch load stroke curve of Solution 2. (b) Punch load stroke curve of Solution 3

However, as the initial extrusion temperature increases, the metal oxidation, decarburization, overheating, and other defects accelerate, resulting in a great reduction in the surface quality and dimensional accuracy of the product. Meanwhile, graphite lubricant is generally used to reduce the friction between the metal and die during warm forming. In fact, graphite lubricant rapidly burns and fails with the increase in temperature. Thus, the lubrication effect is reduced, which is not conducive to deformation. Therefore, the temperature should be reduced as much as possible on the premise of ensuring the sufficient service life of the die when selecting the initial extrusion temperature.

For the outer race investigated in this study, Solutions 2 and 3 can ensure the flow filling of the metal. The damage value of the extrusion part in Solution 2 is approximately $25 \%$ smaller than that in Solution 3. Although the punch load is large, it does not reach the die limit. Under comprehensive consideration, Solution 2 is superior to Solution 3.

4.3 Research on the Extrusion Process of Warm Forming As the outer race is cup/rod-shaped, which has a length reaching $140 \mathrm{~mm}$, the one-time forming of the rod part of the foregoing Solution 2 is feasible, but whether it is considerably different from multiple forming processes is unknown. Therefore, the rod part is changed into secondary extrusion forming, and upsetting is conducted after the extrusion completion of the rod part. Solutions 4 and 2 are compared to reduce the extrusion pressure. Fig. 8 presents the analysis results of Solution 4. 


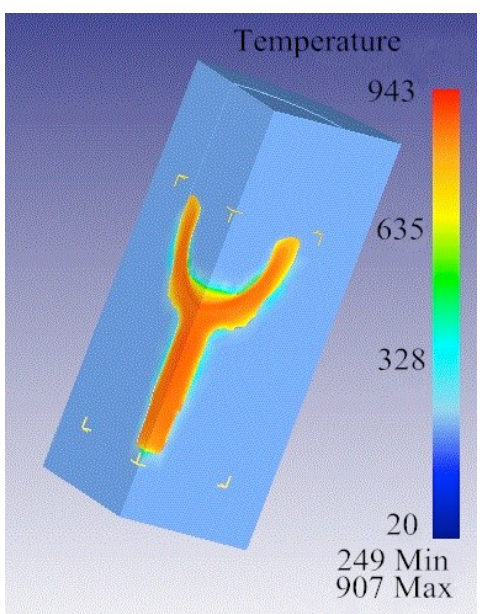

(a)

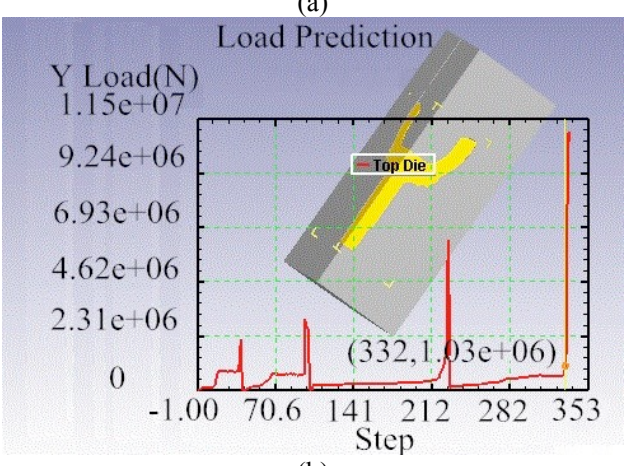

(b)

Fig.8. Punch load stroke curve and extrusion temperature field distribution of Solution 4. (a) Temperature field distribution of extrusion part. (b) Punch load stroke curve

As shown in the temperature distribution in Figure 8, two processes are required, but the temperature of Solution 4 remains within the range of warm forming because the heat generated by deformation offsets the heat dissipation caused by the contact between the billet and die. Therefore, with the increase in working procedure, the metal has low deformation resistance and reduces the maximum forming force.

The punch load in each forming stage can be clearly obtained on the basis of Figure 8(b): the first extrusion $\mathrm{F}=790 \mathrm{KN}$, second extrusion $\mathrm{F}=800 \mathrm{KN}$, upsetting $\mathrm{F}=1180 \mathrm{KN}$, and backward extrusion $\mathrm{F}=1030 \mathrm{KN}$. As $1 / 4$ of the billet is analyzed, its value shall be multiplied by 4 . Hence, the final first extrusion $F=3160 \mathrm{KN}$, second extrusion $\mathrm{F}=3200 \mathrm{KN}$, upsetting $\mathrm{F}=4720 \mathrm{KN}$, and the backward extrusion $\mathrm{F}=4120 \mathrm{KN}$.

In comparison with Solution 2 in Fig. 7, the load is unsubstantially reduced. The maximum load of Solution 2 is $5560 \mathrm{KN}$ and the maximum load of Solution 4 is $4720 \mathrm{KN}$, but the number of procedures is doubled. Therefore, Solution 2 is more advantageous than Solution 4 from the perspectives of simplifying the process, improving the production efficiency, and shortening the production cycle.

\subsection{Optimization of warm forming dies}

To reduce the difficulty of metal flow and enhance the quality of the extrusion parts of the outer race, the die structure and size that affect the metal flow are further optimized on the basis of Solution 2. Fig. 9 presents the specific optimization solution.

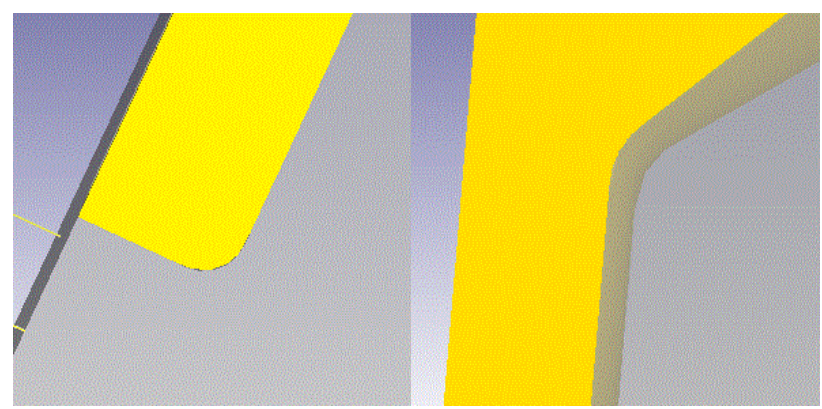

(a)

(b)

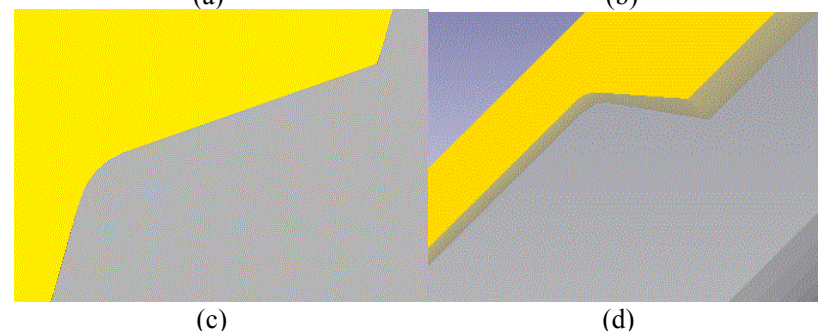

Fig. 9. Die optimization of Solution 2. (a) Optimization of the round angle at the front end of the slender rod. (b) Optimization of the round angle at the main edge of the rod. (c) Optimization of the angle of the initial extrusion (e) Optimization of the round corner of the backward extrusion punch edge

The specific die optimization of Solution 2 is analyzed, and the extrusion pieces with high comprehensive quality are obtained, as shown in Fig. 10. Each part is full of filling and has a small damage value. The temperature is within the range of warm forming and presents a uniform distribution. The maximum equivalent stress is approximately $270 \mathrm{MPa}$. The outer race parts change slightly.

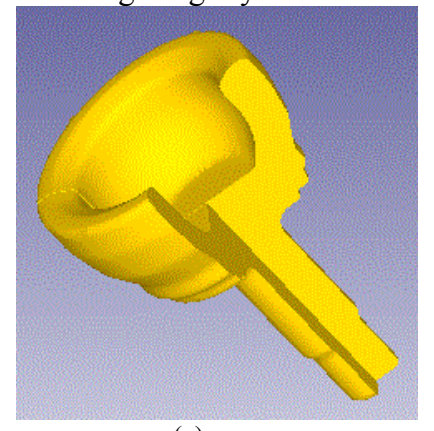

(a)

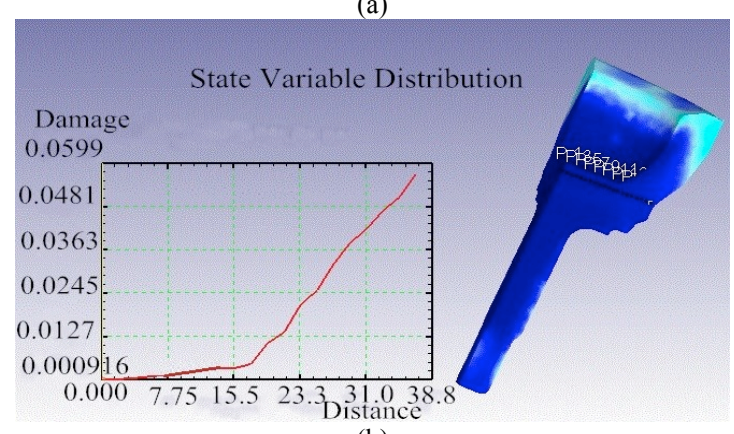

(b)

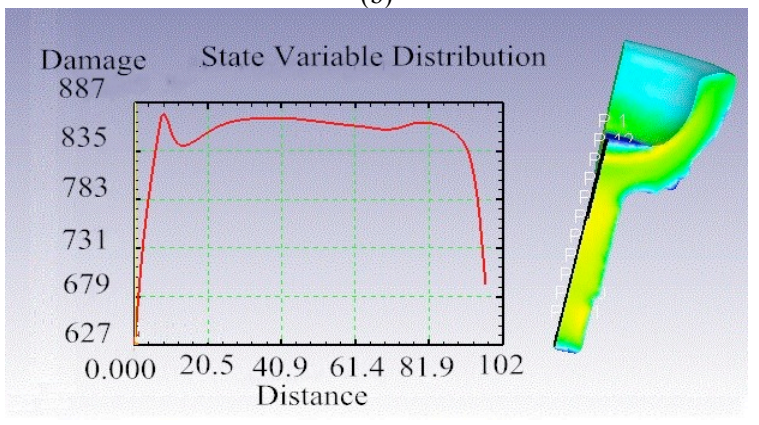

(c) 


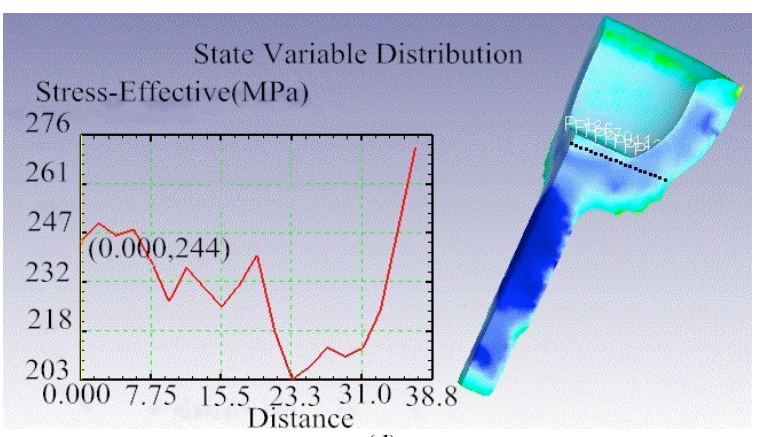

(d)

Fig. 10. Final optimized forming quality. (a) Final extrusion workpiece. (b) Damage value distribution and radial variation curve. (c) Temperature distribution and axial variation curve. (d) Equivalent stress distribution and radial variation curve

\section{Conclusions}

To solve the problem of low forming quality caused by the traditional processing method of outer race, this study presented a method of multistep warm extrusion forming and discussed the optimization of forming process parameters and the forming quality of the method. In this study, the multistep extrusion process for the outer race of four solutions was analyzed with finite element method and Deform tool. Moreover, the influences of billet diameter, initial extrusion temperature, number of working procedures, and die structure on the defects, maximum load, damage value, stress, and temperature during warm forming were evaluated. The following conclusions could be drawn:

(1) The billet diameter should not be too small because it tends to cause folding defects.

(2) Initial extrusion temperature has a great influence on punch load. When selecting the initial extrusion temperature, it should be reduced as much as possible on the premise of ensuring no folding and empty filling in the forming process and sufficient service life of the die.

(3) The increase of working procedure is helpful for reducing the maximum forming force. The workpiece temperature will not change remarkably, but the reduction of the maximum forming force is unsubstantial. In practice, deciding whether to add a working procedure in accordance with the actual production equipment tonnage and bearing capacity of the die is necessary.

(4) For the outer race parts investigated in the study, a high quality of outer race extrusion can be obtained when adopting the short and thick rod billet with the size of $\varphi 60 \mathrm{~mm} \times 100 \mathrm{~mm}$, using the optimized extrusion angle for the first time and the rounded corners of the die, conducting initial extrusion on the rod part at $800{ }^{\circ} \mathrm{C}$, and then conducting the head backward extrusion.

This study combines numerical simulation analysis and theoretical research and proposes an optimization solution suitable for the warm extrusion technology of outer race. The research conclusion about the influences of billet diameter, initial extrusion temperature, number of processes, and die structure on the defects, maximum load, damage, stress, and temperature in the process of forming have a certain reference importance for the warm extrusion forming and die structure design of cup/rod-shaped parts. A further accurate understanding of the influence of forming process parameters and forming quality will be obtained in future studi if the actual outer race production data are combined with the scheme in this study and modified.

\section{Acknowledgements}

This study was supported by the research project of the Nanjing Vocational Institute of Transport Technology (JZ1703).

This is an Open Access article distributed under the terms of the Creative Commons Attribution Licence

\section{References}

1. Hu Y.M., Fu C.F., Zhao J.H., "60 years of development and progress of precision forging forming technology". MW Metal Forming, (15), 2010, pp.1-5.

2. Wang Z.L., Zhao G.Q., Zhao J.H., "Recent condition and developing trends of precise forging technology". Journal of Netshape Forming Engineering, 1(1), 2009, pp.32-38.

3. Li S.Y., Wu H.Q., "Simulation of radial warm extrusion forming for automobile steering rod based on DEFORM-3D". Journal of Plasticity Engineering, 24(4), 2017, pp.213-217.

4. Wang Y.R., "Cup type warm extrusion molding of computer simulation and experimental research". Master thesis of Northwest A\&F University, China, 2017, pp.6-11.

5. Shi C.Y., Li X.D., "Warm extrusion forming process and die design for universal joint pin”. Hot Working Technology, 43(21), 2014, pp.116-119.

6. Su X.B., Mi Y.M. , Gong H.Y., Liao Z.H., "Research on warm extrusion forming and die wear of extemal sleeve with flange". Hot Working Technology, 43(3), 2014, pp.126-128.

7. Sheljaskow S., "Tool lubricating systems in warm forging". Journal of Materials Processing Technology, 113(1), 2001, pp.16-21.

8. Eghbali B., Shaban M., Sheljaskow S., "Warm deformation of low carbon steel using forward extrusion-equal channel angular pressing technique". Journal of Iron and Steel Research International, 20(2), 2013, pp.68-71.
9. Yoon J.H., Lee J.H., "Process design of Warm-Forging with extruded Mg-8Al-0.5Zn alloy for differential case in automobile". International Journal of Precision Engineering and Manufacturing, 16(4), 2015, pp.841-846.

10. Yoon J.H., Lee S.I., "Warm forging of magnesium AZ80 alloy for the control arm in an automobile". Proceedings of the Institute of Mechanic Engineers, Part D: Journal of Automobile Engineering, 229(13), 2015, pp.1732-1738.

11. Choi C., Groseclose A., Altan T., "Estimation of plastic deformation and abrasive wear in warm forging dies". Journal of Materials Processing Technology, 212(8), 2012, pp.1742-1752.

12. Martinkovic M., Kapustova M., Kravarik L., "Optimization and verification of warm forging temperature of steel”. In: Proceedings of the 22nd International DAAAM Symposium Annals, Vienna, Austria: DAAAM International, 2011, pp.201-202.

13. Liu W., Kong D. J., "Effects of warm extrusion temperatures on corrosion performance of 40Cr steel". Corrosion Engineering Science and Technology, 53(8), 2018, pp.481-486.

14. Yang L.Q., Lv Q.Q., Zhang H.M., Zhu C.H., Wang W.Z., "Structural strength and service life of the extrusion forming die for agricultural engine piston heads". Strength of Materials, 50(1), 2018, pp.107-115.

15. Torkian A.,Faraji G., Karimpour M., "Mechanical properties and microstructure of WE43 Mg alloy processed by warm ECAP followed by extrusion". Archives of Metallurgy and Materials, 63(3), 2018, pp.1093-1100. 